\title{
Presence of GB Virus $C$ in Whole-Blood Derivatives: A Pilot Study
}

Mishar Kelishadi (PhD Candidate) Laboratory Sciences Research Center, Golestan University of Medical Science, Gorgan, Iran and Department of Virology, Pasteur Institute of Iran, Tehran, Iran

Pezhman Hashemi (PhD) Laboratory Sciences Research Center, Golestan University of Medical Science, Gorgan, Iran

G.Hossein Ashrafi (PhD) Kingston University London, Cancer Theme, School of Life Science, Pharmacy and Chemistry, SEC Faculty, Kingston upon Thames, KT12EE, London, UK

Naser Behnampour (PhD) Department of Statistic, Paramedical School, Golestan University of Medical Sciences, Gorgan, Iran

Alijan Tabarraei (PhD)

Infectious Diseases Research Center Golestan University of Medical

Sciences, Gorgan, Iran

Corresponding author: Alijan Tabarraei

Tel: $+98-1732422652$

E-mail: alijant@yahoo.com

Address: Infectious Diseases Research Centre, Department of Microbiology, Golestan University of Medical Sciences, Gorgan, Iran

Received: 22 Jul 2018

Revised: 10 May 2018

Accepted: 1 Jun2019

\section{c) (i) (8)}

This work is licensed under a Creative Commons Attribution 4.0 License.

\begin{abstract}
Background and Objectives: Red blood cell (RBC) transfusion is necessary for the prevention and treatment of a variety of life-threatening injuries and diseases. However, viral contamination of these products is a great threat to recipients. Screening donors for GB virus $C$ by nucleic acid testing is not routinely implemented worldwide. The aim of the present study was to evaluate prevalence of GBV-C RNA in whole blood/red cell components.

Methods: In this cross sectional pilot study, we collected 153 units of packed RBCs from blood banks of two public hospitals in Gorgan (northeast of Iran), between 0ctober and November 2014. The samples were screened for the presence of GBV-C RNA in plasma by nested RT-PCR using specific primers targeting highly conserved regions of 5' UTR of GBV-C. Data were analyzed using SPSS software (version 18).

Results: 0verall, 40 (31.37\%) whole blood or red cell components were positive for GBV-C viremia. The GBV-C RNA was detected in 31/80 citrate phosphate dextrose-adenine 1 (CPDAl) RBC, 16/50 washed RBC and 1/13 reduced-leukocyte RBC. However, whole blood CPDAl was negative for GBV-C viremia. Direct sequencing of PCR products confirmed GBV-C contamination.

Conclusions: Transmission of GBV-C infection was observed in blood products. Thus, efforts should be made to develop new strategies for assuring blood transfusion safety.

Keywords: Molecular testing, Epidemiology, Transfusion-transmissible infections, GB Virus C.
\end{abstract}

This paper should be cited as: Kelishadi M, Hashemi $P$, Ashrafi GH, Behnampour N, Tabarraei A[Presence of GB Virus $C$ in Whole-Blood Derivatives: A Pilot Study]. mljgoums. 2019; 13(5):26-31 


\section{INTRODUCTION}

GB virus $\mathrm{C}$ (GBV-C) is a widely distributed lymphotropic human virus discovered in 1995, which is found in 0.9 to $20 \%$ of healthy blood donors throughout the world $(1,2)$. It has been recently proposed to classify GBV-C, along with GBV-A and GBV-D, as members of a fourth genus within the Flaviviridae named 'Pegivirus' (1). The transmission routes of GBV-C are not completely known. However, similar to other lymphotropic viruses, GBV-C is transmitted vertically, sexually and via exposure to contaminated blood/blood products (1).

Although GBV-C was initially considered as a possible etiological agent of viral hepatitis in humans, to date, there is no definite evidence for the involvement of GBV-C in liver diseases $(2,3)$. The majority of patients infected with GBV-C via blood products, do not develop chronic hepatitis, but GBV-C has been detected in many patients with chronic hepatitis (4). A few investigations have suggested involvement of GBV-C in hepatitis, hepatocirrhosis and possibly in hepatocellular carcinoma (5).

GBV-C infection may persist for decades, but most healthy individuals clear viremia within 2 years of infection (1). GBV-C infections are usually asymptomatic, transient and selflimiting, with slight or no elevation of alanine aminotransferase. It has been proposed that GBV-C itself cannot cause hepatitis, and coinfection with GBV-C does not alter the clinical course of community-acquired hepatitis A, B or C (6). Also, GBV-C is thought to be associated with prolonged survival in HIV-positive individuals $(1,7)$. Although the virus has not been clearly linked to any human disease, it has been shown that GBV-C does not replicate in hepatocytes but rather in lymphocytes $(1,8)$, thus suggesting the possible extrahepatic pathogenicity of the virus $(9,10)$.

There are several reports of an association between GBV-C and hepatitis-associated aplastic anemia besides other hepatitis-causing viruses $(3,6,8)$. In addition, an association between GBV-C and hepatitis B virus (HBV) co-infection and pathogenesis of nonHodgkin's lymphoma has been demonstrated. Moreover, the potential association of the virus with hematological disorders and hematological malignancies has been suggested $(6,11,12)$.
A study in America confirmed the presence of GBV-C in brain specimens from deceased patients with progressive multiple sclerosis by deep sequencing method (8). Screening GBV$\mathrm{C}$ infection in different populations showed that the virus may be associated with persistent infection or graft rejection in immunosuppressed patients, such as transplant recipients, patients with chronic renal failure, HIV-infected patients, patients on hemodialysis, intravenous drug users and patients with thalassemia or leukemia (6-8).

Since no GBV-C nucleic acid testing has yet been proposed for whole blood or red blood cell (RBC) components in Iran, this study was designed to determine the frequency of GBV$\mathrm{C}$ infection in $\mathrm{RBC}$ products in Gorgan, north east of Iran.

\section{MATERIALS AND METHODS}

In this cross sectional pilot study, we collected 153 units of packed RBCs [citrate phosphate dextrose-adenine 1 (CPDA1) RBC $(n=88)$ ], washed RBC $(n=50)$, whole blood CPDA1 $(n=2)$, leukocytes-reduced RBC $(n=13)]$ from blood bank of two public hospitals in Gorgan. Blood specimens were collected while patients were being transfused. The study was performed between October and November 2013 in the Department of Virology at Golestan University of Medical Sciences, Gorgan, Iran. Ethical approval was obtained from the Ethics Committee of Faculty of Medicine, Golestan University of Medical Sciences (with code of practice 20199207149). Plasma was separated, aliquoted and finally stored at $-70{ }^{\circ} \mathrm{C}$ until processing. Briefly, RNA was extracted from $200 \mu \mathrm{l}$ of plasma using the High Pure Extraction Kit (Roche Diagnostics $\mathrm{GmbH}$, Mannheim, Germany) according to the manufacturer's instructions. GBV-C RNA was detected by nested reverse transcriptase polymerase chain reaction (RT-nested-PCR) using primers from highly conserved regions of 5' untranslated region of GBV-C PNF2161 isolates based on the reference sequences from GeneBank, as previously described (6) (Table $1)$.

The first-round PCR amplification was performed in a $25 \mu \mathrm{L}$ reaction volume containing $1 \mu \mathrm{L}$ cDNA, 10 pmol of each universal outer forward and reverse primers (Table 1), $0.2 \mathrm{mM}$ of each deoxynucleotide (dNTP) (Genet Bio, Korea), 1.25 U of Taq 
DNA polymerase (Genet Bio, Korea), $1.5 \mathrm{mM}$ $\mathrm{MgCl}_{2}$ (Genet Bio, Korea) and $2.5 \mu \mathrm{l} 10 \mathrm{X}$ PCR buffer (Genet Bio, Korea). The reactions were performed in a thermal cycler (PeQlab, Erlangen, Germany). The reagents for the second-round PCR were the same as the ones used in the first round, except for the volume of template DNA $(0.5 \mu \mathrm{L})$. Reactions were performed in a Peq Lab thermal cycler (Primus Advanced 96 thermal cycler, USA) with the following cycling conditions: $95^{\circ} \mathrm{C}$ for $5 \mathrm{~min}$; 30 cycles of $94{ }^{\circ} \mathrm{C}$ for $50 \mathrm{~s}, 55^{\circ} \mathrm{C}$ for $40 \mathrm{~s}, 72$ ${ }^{\circ} \mathrm{C}$ for $50 \mathrm{~s}$; and $72{ }^{\circ} \mathrm{C}$ for $5 \mathrm{~min}$. Amplification for the second round was carried out under the following conditions: 95 ${ }^{\circ} \mathrm{C}$ for $5 \mathrm{~min}$; 25 cycles of $94{ }^{\circ} \mathrm{C}$ for $50 \mathrm{~s}, 70$ ${ }^{\circ} \mathrm{C}$ for $40 \mathrm{~s}, 72{ }^{\circ} \mathrm{C}$ for $50 \mathrm{~s}$, and $72{ }^{\circ} \mathrm{C}$ for 5 $\min$.

All PCR contamination precautions were taken. Negative controls consisting of sera from subjects with no GBV-C markers were obtained from Digestive Disease Research Institute of Shariati Hospital, Tehran
University of Medical Sciences, Iran. PCR procedures were carefully optimized.

The PCR products were electrophoresed on $2 \%$ agarose gel stained with ethidium bromide and were visualized under ultraviolet light (Figure 1).

Data were analysed using the SPSS software (version 18, SPSS, Chicago, IL, USA). Frequency and 95\% confidence intervals were calculated. The Chi-square test or Fisher's exact test were used for comparison of data. Pvalues less than 0.05 were considered statistically significant.

\section{RESULTS}

Of 153 whole blood or RBC components, 48 (31.37\%) were positive for GBV-C viremia, including 31 (64.58\%) CPDA1 RBC, 16 (33.34\%) washed RBC and one $(2.08 \%)$ reduced-leukocyte $\mathrm{RBC}$ samples. However, whole blood CPDA1 was negative for GBV-C viremia. Direct sequencing of PCR products confirmed GBV-C contamination.

Figure 1-Agarose gel electrophoresis of the PCR products. From left: Lane 1: DNA ladder (100 bp), Lane 2: negative control, Lane 3: positive control, Lane 4: GBV-C-positive specimens.

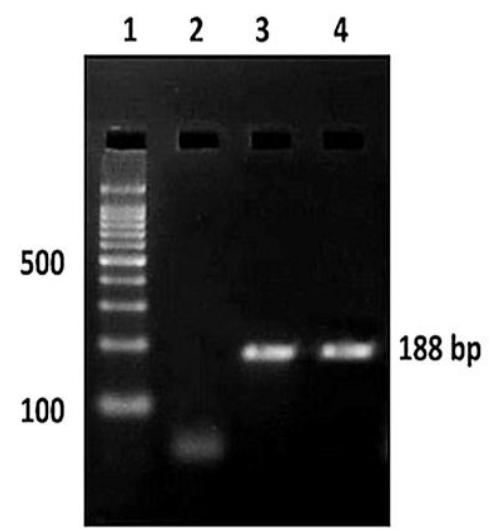

Table 1-Sequences and positions of the primers used for amplification of GBV-C genome

\begin{tabular}{ccccc}
\hline Primer & Region & Position & Polarity & Sequence (5' to 3') \\
\hline HG1 & $5^{\prime}$ 'UTR & $139-158$ & Sense & 5'-GGTCGTAAATCCCGGTCACC-3' \\
HG1R & $5^{\prime}$ 'UTR & $381-400$ & Antisense & 5'-CCCACTGGTCCTTGTCAACT-3' \\
HG2 & $5^{\prime}$ 'UTR & $163-182$ & Sense & 5'-TAGCCACTATAGGTGGGTCT-3' \\
HG2R & $5^{\prime}$ 'UTR & $331-350$ & Antisense & 5'-ATTGAAGGGCGACGTGGACC-3' \\
\hline
\end{tabular}

\section{DISCUSSION}

RBC transfusion is necessary for the prevention and treatment of a variety of lifethreatening injuries and diseases and also to replace blood lost due to surgery and childbirth. However, viral contamination of these products is a great threat to patients $(13,14)$. Each year, approximately $2,000,000$ units of RBC or whole blood are transfused in Iran (14). The following strategies have evolved over the recent years for reducing risk of post-transfusion infections: A) careful selection of donors, B) routine screening of blood donors (whole blood) and plasma derivatives for $\mathrm{HBV}$ surface antigen and $\mathrm{HBV}$ 
DNA, hepatitis $\mathrm{C}$ virus (HCV) antibodies and HCV RNA, HIV-1 and -2 antibodies and HIV1 RNA, human T-cell lymphotropic virus 1-2 antibodies (in high-incidence areas) and cytomegalovirus antibodies (15), C) viral removal/inactivation technologies, notably dual viral inactivation (solvent/detergent and heat treatment) of blood products and plasma derivatives except whole blood or RBC components $(14,16)$.

Due to implementation of the above methods, the risk of transmission of blood-borne viruses, especially $\mathrm{HBV}, \mathrm{HCV}$ and $\mathrm{HIV}$, through plasma and plasma products has been reduced significantly or eliminated in many areas of the world $(16,17)$. Despite these improvements, transmission of viruses such as parvovirus B19, transfusion-transmitted virus, SEN-V virus, West Nile virus, cytomegalovirus, HBV (mutants, occult) and prions through blood transfusion has been rarely reported $(16,18)$. In addition, approximately 1,000 people receive GBV-C viremic blood products daily in the USA (1).

In the present study, we screened samples from whole blood CPDA1, CPDA1 RBC, washed RBC (washed to reduce plasma proteins for reducing the risk of allergic reactions) and leukocyte-reduced RBC (filtered to remove most leukocytes for reducing the risk of febrile transfusion reactions and viral infection, such as cytomegalovirus) products. A high frequency $(31.5 \%)$ of GBV-C viremia was observed in whole blood or RBC products, which is surprisingly higher than the rate of GBV-CRNA positivity in healthy blood donors ( 0.9 to $20 \%$ ) and high risk individuals (1 to $43.6 \%$ ), suggesting the likely transmission of the virus via contaminated environmental surfaces (6).

The virus was detected in almost all types of RBC components but absent in whole blood CPDA1, which might be related to the small whole blood CPDA1 sample size. In addition, blood bag manufacturers were from three different countries. GBV-C-RNA positivity was notably more common in plastic bags made by a particular manufacturer, which could be due to the larger sample size. Nevertheless, there was no correlation between GBV-C contamination and blood bag.

Previous studies show that vials of clotting factor concentrates treated by pasteurization, solvent detergent or dry heat for $144 \mathrm{~h}$, were negative for the presence of GBV-C, and all samples that had not undergone a specific viral inactivation step were positive for GBV-C (19, 20). However, a study demonstrated that HIVpositive patients with haemophilia are at an increased risk of GBV-C infection; despite treatment with virus inactivated clotting factor concentrates. Nevertheless, the emergence of markers of GBV-C infection can be a result of progression of immune impairment in the course of HIV infection (21). Current purification and viral inactivation techniques against viruses such as GBV-C seems to be very effective $(19,20)$.

Due to unavailability of blood donors' sera prior to initiation of the procedures, precontamination of the individuals with infectious could not be determined. It is important to note that all samples did not undergo a specific viral inactivation step. In Iran, screening of donors and donated blood is carried out mainly to improve virus safety of whole blood or RBC components. Additionally, screening is limited to certain viruses. Thus, the high frequency of GBV-C in the tested whole-blood derivatives is not surprising. Consistent with our findings, some studies reported that products that had not undergone a specific viral inactivation step, were positive for GBV-C $(20,22)$. However, further studies are necessary to confirm this epidemiological observation.

Our investigation was confined to red cell products and other products such as plasma derivatives were not tested, which could be a limitation of this study. Thus, generalization of our findings requires conducting studies in different geographical areas with larger sample sizes from various blood products. The preferred sampling frame for our study was based on the information on the used blood bags, which produced satisfying data. Acquisition of additional data including individual characteristics such as age, gender, etc. requires further cooperation from the Iranian Blood Transfusion Organization.

The Food and Drug Administration does not recommend blood screening for GBV-C, because it seems to be a virus that does little harm to recipients $(1,19)$. It is important to note that most of the attention paid to GBV-C has been due to its possible involvement in liver diseases. However, specific variants of GBV-C are thought to be aggressive (3). This may have important implications for blood safety. We believe that in countries such as 
Iran where incidence of GBV-C infection is high, the introduction of GBV-C-negative donors for "GBV-C-safe" would be desirable.

The complete removal or inactivation of every virus particle in blood products is a worthy but currently impractical goal. Latest approaches for reduction of infectivity include the use of new generation of S-303 PIT and two pathogen reduction technologies-methylene blue plus light and shortwave ultraviolet light (23); robust methods for accurate diagnosis using pan-microbiological oligonucleotide microarrays $(24,25)$; and obtaining stem cellderived blood products $(17,26)$.

However, more studies are necessary to thoroughly examine the impact of these technologies on RBCs, which may lead to formation of undesirable antibodies in the recipient.

\section{CONCLUSION}

To date, this is the first study to screen whole blood/red cell components for GBV-C RNA in Iran. Today, no country has decided to screen blood donors for GBV-C. Although the implementation of inactivation/removal methods designed to

\section{REFERENCES}

1. Bhattarai N, Stapleton JT. GB virus C: the good boy virus?. Trends in microbiology. 2012; 20(3): 124-30. doi: 10.1016/j.tim.2012.01.004.

2. Cheung RC, Keeffe E, Greenberg H. Hepatitis G virus: is it a hepatitis virus?. Western journal of medicine. 1997; 167(1): 23-23.

3. Halasz R, Barkholt L, Lara C, Hultgren C, Ando Y, Broomé U, et al. Relation between $G B$ virus C/hepatitis $G$ virus and fulminant hepatic failure may be secondary to treatment with contaminated blood and/or blood products. Gut. 1999; 44(2): 274-8.

4. Fallahian F, Alavian S, Rasoulinejad M. Epidemiology and transmission of hepatitis $G$ virus infection in dialysis patients. Saudi Journal of Kidney Diseases and Transplantation 2010; 21(5): 831-4.

5. Kew M. Hepatitis viruses (other than hepatitis $B$ and $C$ viruses) as causes of hepatocellular carcinoma: an update. Journal of viral hepatitis. 2013; 20(3): 149-57. doi: 10.1111/jvh.12043.

6. Kelishadi M, Mojerloo M, Moradi A, Bazouri M, Hashemi P, Samadi S, et al. GB virus $C$ Viremia and Anti-E2 Antibody Response Among Hemodialysis Patients in Gorgan, Iran. Jundishapur Journal of Microbiology. 2014; 7(11): e13122. doi: 10.5812/jjm.13122.

7. Ranjbar MM, Ghorban K, Alavian SM, Keyvani H, Dadmanesh M, Roayaei Ardakany A, et al. GB Virus C/Hepatitis $G$ Virus Envelope Glycoprotein E2: Computational Molecular Features and Immunoinformatics Study. Hepatitis monthly. 2013; 13(12): e15342. doi: 10.5812/hepatmon. 15342. prevent viral derived products, whole blood or red cell components cannot undergo viral inactivation procedures. Furthermore, transmission of GBV-C infection was observed in RBC preparations; hence, GBV-C can be considered as a representative virus that could indicate presence of known and unknown transmissible agents with physical properties.

\section{ACKNOWLEDGEMENTS}

We would like to thank the Laboratory Sciences Research Center of Golestan University of Medical Sciences for the continuous encouragement during this study and also the emergency departments of Taleghani and 5th Azar Medical Centres for providing the valuable specimens.

\section{AUTHORS' CONTRIBUTION}

All authors discussed the results and implications and commented on the manuscript at all stages.

\section{CONFLICT OF INTEREST}

The authors declare that there is no conflict of interest.

8. Kriesel JD1, Hobbs MR, Jones BB, Milash B, Nagra $\mathrm{RM}$, Fischer $\mathrm{KF}$, et al. Deep sequencing for the detection of virus-like sequences in the brains of patients with multiple sclerosis: detection of $G B V-C$ in human brain. PLoS One. 2012; 7(3): e31886. doi: 10.1371/journal.pone.0031886.

9. Arroyave JC, Pujol FH, Navas MC, Cortes-Mancera F. Interaction between $H I V-1$ and $G B$ virus type-C during coinfection status. Revista chilena de infectologia: organo oficial de la Sociedad Chilena de Infectologia. 2013; 30(1): 31-41. DOI: 10.1590/S071610182013000100005 .

10. Blanc PL1, Boumrazne R, Sarzier JM, Forel C. Extrahepatic symptoms in the course of $G B V-C / H G V$ infection. Med Mal Infect. 2009; 39(4): 264-6. doi: 10.1016/j.medmal.2008.09.030.

11. Khodavandi A, Yaghobi R, Alizadeh F, Mirzaee M, Roshan nia M, Ramzi M. Evaluation of $G B$ virus $C$ $(G B V-C)$ /hepatitis $G$ virus $(H G V)$ and hepatitis type $B$ viruses $(H B V)$ infections in patients with non-Hodgkin's lymphoma. African Journal of Microbiology Research. 2011; 5(24): 4143-9.

12. Ahmed QMU. Hepatitis G virus (HGV): where we stand and what to do? International Journal of Immunological Studies. 2011; 1(3): 255-63. DOI:10.1504/IJIS.2011.041723

13. Naito H, Win KM, Abe K. Identification of a novel genotype of hepatitis $G$ virus in Southeast Asia. Journal of clinical microbiology. 1999; 37(4): 1217-20. 
14. Kelishadi M, Moradi A, Samadi S, Hashemi P, Bazouri M, Tabaraei A. Transfusion-Transmitted Cytomegalovirus Infection (TT-CMV): A Pilot Study on Safety of Whole-Blood Derivatives. Scimetr. 2015; 3(3): e25718.

15. Ghanbari R, Ravanshad M, Hosseini SY, Yaghoubi $\mathrm{R}$, Shahzamani k. Genotyping and infection rate of $G B V$ $C$ among Iranian HCV-infected patients. Hepatitis monthly. 2010; 10(2): 80-7.

16. Organization WH. Guidelines on viral inactivation and removal procedures intended to assure the viral safety of human blood plasma products. WHO Technical Report, Series. 2004; 924.

17. Gajewski JL, Johnson VV, Sandler SG, Sayegh A, Klumpp TR. A review of transfusion practice before, during, and after hematopoietic progenitor cell transplantation. Blood. 2008; 112(8): 3036-47.

18. Soucie JM, De Staercke C, Monahan PE, Recht M, Chitlur MB, Gruppo R, et al () Evidence for the transmission of parvovirus $B 19$ in patients with bleeding disorders treated with plasma-derived factor concentrates in the era of nucleic acid test screening. Transfusion. 2013; 53(6): 1217-25.

19. Lefrère JJ, Laperche S, Roudot-Thoraval F. Hepatitis $G$ virus: a suitable marker of in vivo efficacy for pathogen inactivation. Vox sanguinis. 2008; 95(1):76-8

20. Alonso-Rubiano E1, Gerber M, Friedman P, Hodges $\mathrm{S}$, Leissinger C. Hepatitis $G$ virus in clotting factor concentrates. Haemophilia. 2003; 9(1): 110-5.

21. Woelfle J1, Berg T, Bialek R, Keller KM, Effenberger W, Wagner N. GB virus C/hepatitis $G$ virus infection in HIV infected patients with haemophilia despite treatment with virus inactivated clotting factor concentrates. Archives of disease in childhood. 1999; 80(5): 429-32.
22. Hofer H, Aydin I, Neumueller-Guber S, Mueller C, Scherzer TM, Staufer K, et al. Prevalence and clinical significance of $G B$ virus type C/hepatitis $G$ virus coinfection in patients with chronic hepatitis $C$ undergoing antiviral therapy. J Viral Hepat. 2011; 18(7): 513-7. doi: 10.1111/j.1365-2893.2010.01340.x.

23. Steinmann E, Gravemann U, Friesland M, et al. Two pathogen reduction technologies-methylene blue plus light and shortwave ultraviolet light-effectively inactivate hepatitis $C$ virus in blood products. Transfusion. 2013; 53(5): 1010-8. doi: 10.1111/j.15372995.2012.03858.x.

24. Kang X1, Qin C, Li Y, Liu H, Lin F, Li Y, et al. Improvement of the specificity of a pan-viral microarray by using genus-specific oligonucleotides and reduction of interference by host genomes. Journal of medical virology. 2011; 83(9): 1624-30.

25. Liu Y, Sam L, Li J, Lussier YA. Robust methods for accurate diagnosis using pan-microbiological oligonucleotide microarrays. BMC bioinformatics. 2009; 10(Suppl 2): S11. doi: 10.1186/1471-2105-10-S2-S11.

26. Ebihara Y, Ma F, Tsuji K. Generation of red blood cells from human embryonic/induced pluripotent stem cells for blood transfusion. International journal of hematology. 2012; 95(6): 610-6. doi: 10.1007/s12185012-1107-9. 